\title{
Prediction of BRCA1 Germ-Line Mutation Status in Patients with Breast Cancer Using Histoprognosis Grade, MS110, Lys27H3, Vimentin, and KI67
}

\author{
Mohamed Hassanein ${ }^{a, b} \quad$ Laetitia Huiart $^{a} \quad$ Violaine Bourdon $^{a} \quad$ Laetitia Rabayrol $^{a}$ \\ Jeanine Geneix ${ }^{c}$ Catherine Nogues ${ }^{f}$ Jean Philippe Peyrat ${ }^{g} \quad$ Paul Gesta $^{\text {h }}$

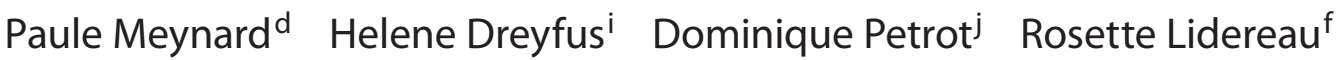 \\ Tetsuro Noguchi ${ }^{a}$ François Eisinger ${ }^{a}$ Jean Marc Extrab ${ }^{b}$ Patrice Viens ${ }^{b}$ e \\ Jocelyne Jacquemier ${ }^{c}$ Hagay Sobola, e

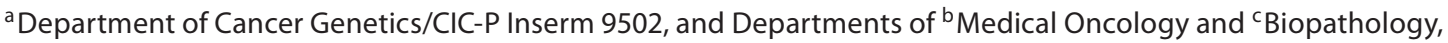 \\ Paoli Calmettes Institute, ${ }^{d}$ Laboratory of Pathology, and ${ }^{\mathrm{e}}$ Regional Teaching Unit of Medicine, University of \\ Aix-Marseille II, Marseille, ${ }^{\mathrm{f}}$ Department of Pathology, Centre René-Huguenin, Saint-Cloud, ${ }^{\mathrm{g}}$ Laboratory of Human \\ Molecular Oncology, CRLCC Oscar Lambert, Lille, h Pôle Oncologie, Oncogénétique Poitou-Charentes, Niort, \\ 'Institut Ste Catherine, Avignon, and 'ं Laboratory of Pathology, Rochelle, France
}

\section{Key Words}

BRCA1 - Germ-line mutation - Sequencing - Tissue microarray - Chromosome $X \cdot$ Hereditary breast cancer • Treatment tailoring $\cdot$ PARP inhibitor

\footnotetext{
Abstract

Family structure, lack of reliable information, cost, and delay are usual concerns when deciding to perform BRCA analyses. Testing breast cancer tissues with four antibodies (MS110, lys27H3, vimentin, and $\mathrm{KI} 67$ ) in addition to grade evaluation enabled us to rapidly select patients for genetic testing identification. We constituted an initial breast cancer tissue microarray, considered as a learning set, comprising 27 BRCA1 and 81 sporadic tumors. A second independent validation set of 28 BRCA1 tumors was matched to 28 sporadic tumors using the same original conditions. We investigated morphological parameters and 21 markers by immunohistochemistry. A logistic regression model was used to select the minimal number of markers providing the best model to predict BRCA1 status. The model was applied to the validation
}

set to estimate specificity and sensibility. In the initial set, univariate analyses identified 11 markers significantly associated with BRCA1 status. Then, the best multivariate model comprised only grade 3, MS110, Lys27H3, vimentin, and KI67. When applied to the validation set, BRCA1 tumors were correctly classified with a sensitivity of $83 \%$ and a specificity of $81 \%$. The performance of this model was superior when compared to other profiles. This study offers a new rapid and cost-effective method for the prescreening of patients at high risk of being BRCA1 mutation carriers, to guide genetic testing, and finally to provide appropriate preventive measures, advice, and treatments including targeted therapy to patients and their families.

Copyright $\odot 2013$ S. Karger AG, Basel

\section{Introduction}

The incidence of breast cancer (BC) has increased over the last 20 years in developed countries [1]. About $5 \%$ of these patients have a family history of BC. The identifica-

\section{KARGER}

E-Mail karger@karger.com

www.karger.com/pat
(C) 2013 S. Karger AG, Basel

$1015-2008 / 13 / 0805-0219 \$ 38.00 / 0$ 
tion of the BRAC1 gene in 1994 [2] resulted in modification of the care management of families where a germline mutation has been found. The BRCA1 germ-line mutation is identified in $40-50 \%$ of hereditary BC cases [3]. The lifetime risk of developing BC in BRCA1 mutation carriers lies between 52 and $85 \%$ depending on the age and population tested versus $8 \%$ in the general population [4].

The BRCA1 gene localized in the chromosome 17q21 region is a large gene with 24 exons (a coding sequence of about $5.7 \mathrm{~Kb}$ ). The BRCA1 gene codes for a protein of 1,863 amino acids and $220 \mathrm{kDa}$ with a functional binding zinc ring finger region in the $\mathrm{N}$-terminal.

Many functions are related to the BRCA1 gene, such as regulation of the cellular cycle through the control gate G2/M and DNA repair [5], and it thus acts as a guard of genome integrity. A role in the inactivation of the second $\mathrm{X}$ chromosome has been reported [6]. Interaction with other genes (P53, Bcl2, RAD51, and ATM) [7] has been described. The majority of deleterious mutations lead to a putative truncated, unstable, absent, or delocalized proteins [8]. In addition, the BRCA1 protein level can vary in the absence of germ-line mutations in sporadic BC, particularly in the basal phenotype (BP) where up to a $30 \%$ reduction in the BRCA1 protein level has been reported [ 9 , 10]. To explain this reduction in BRCA1 protein expression, several other mechanisms of inactivation have been suggested such as loss of heterozygosity, promoter methylation [11], and reduction of the mRNA level [12] or a second hit, according to Knudson's second hit theory [13].

As deleterious germ-line mutations may occur in the whole coding region, BRCA1 mutation search is usually a long and expensive task. Consequently genetic testing cannot be offered systematically to all BC patients. Thus, it is necessary to preselect among the patients those considered to be at high genetic risk. In order to estimate the likelihood of being a BRCA1 mutation carrier, statistical models such as BRCAPRO, the Manchester scoring system (MSS), and Bodicea [14] have been established depending on the family history and the age of cancer onset. The efficacy and reliability of such models is dependent on the family structure, the source of data, the incorporated risk factors, and the nature of the calculations the model algorithms are based upon. Limitations of such models comprise the small size of pedigrees, the limited number of informative women, and the absence of medical information on family members [15].

Other less conclusive models have been proposed without - up to now - clinical application because of a lack of reliability of the models [16].
However, the most appropriate prevention (prophylactic surgery) [17] and care management strategies [17, 18] can only be offered if a mutation search is rapidly carried out. Such clinical issues have given rise to other prescreening approaches based on individual parameters. Thus, it has been suggested that several profiles are overrepresented among BRCA1 gene carriers as follows: grade 3 and ER negativity [19] or triple-negative tumors (ER, PR, and HER2 negative) [20, 21], BP [22, 23], and medullary BC [24]. Models based on a combination of morphological profiles and ages at cancer onset have also been used [19]. However, even if an overlap between these profiles exists, it is not known if they correspond to different clinical entities. Furthermore the performance and reproducibility of these models depend on the series of cases under study and on the definition used to select the cases.

Our study proposes a simple, rapid, reproducible, and low-cost prescreening test to improve the identification of BRCA1 mutation carriers using a profile based on morphological and immunohistochemical (IHC) features combining both current $\mathrm{BC}$ markers and innovative parameters exploring the Brcal protein, loss of $\mathrm{X}$ chromosome inactivation, cell origin, and markers selected from genomic expression profiling.

\section{Materials and Methods}

\section{Population}

An initial learning set comprised 27 BRCA1 mutated $\mathrm{BC}$ and 81 sporadic $\mathrm{BC}$ obtained from patients matched with the same age group. All tissues were included in a tissue microarray (TMA) block constructed in triplicate to avoid loss of information. These tissues were obtained from the tumor bank of the Paoli Calmettes Institute. For each BRCA1 mutated BC, 3 controls of sporadic BC were selected $(n=81)$. Controls were matched to cases by age groups. In order to obtain a close match, 6 age groups were defined. Histological types in BRCA1-mutated BC were ductal ( $\mathrm{n}=$ $18)$, medullary $(n=5)$, tubular $(n=1)$, lobular $(n=1)$, Malpighian $(\mathrm{n}=1)$, and metaplasic $(\mathrm{n}=1)$, while in sporadic cases 66 were ductal, 6 were tubular, 6 were lobular, 1 was Malpighian, 2 were mixed, and 0 were medullary.

A validation set was composed of 28 independent BRCA1-mutated $\mathrm{BC}$ that were matched for age with 28 sporadic $\mathrm{BC}$ in the same original conditions. BRCA1 tumors in the validation set were provided by 5 different centers through the French Cooperative Network on Cancer Genetics of the National Federation of Cancer Centers. For each case, the center which provided the case also provided an age-matched sporadic control. The validation set underwent the same procedure of mutation identification as the initial set. TMA, histological staining, and slide reading were centrally carried out by the same people. 
Table 1. Description of the antibodies and immunohistochemical techniques used

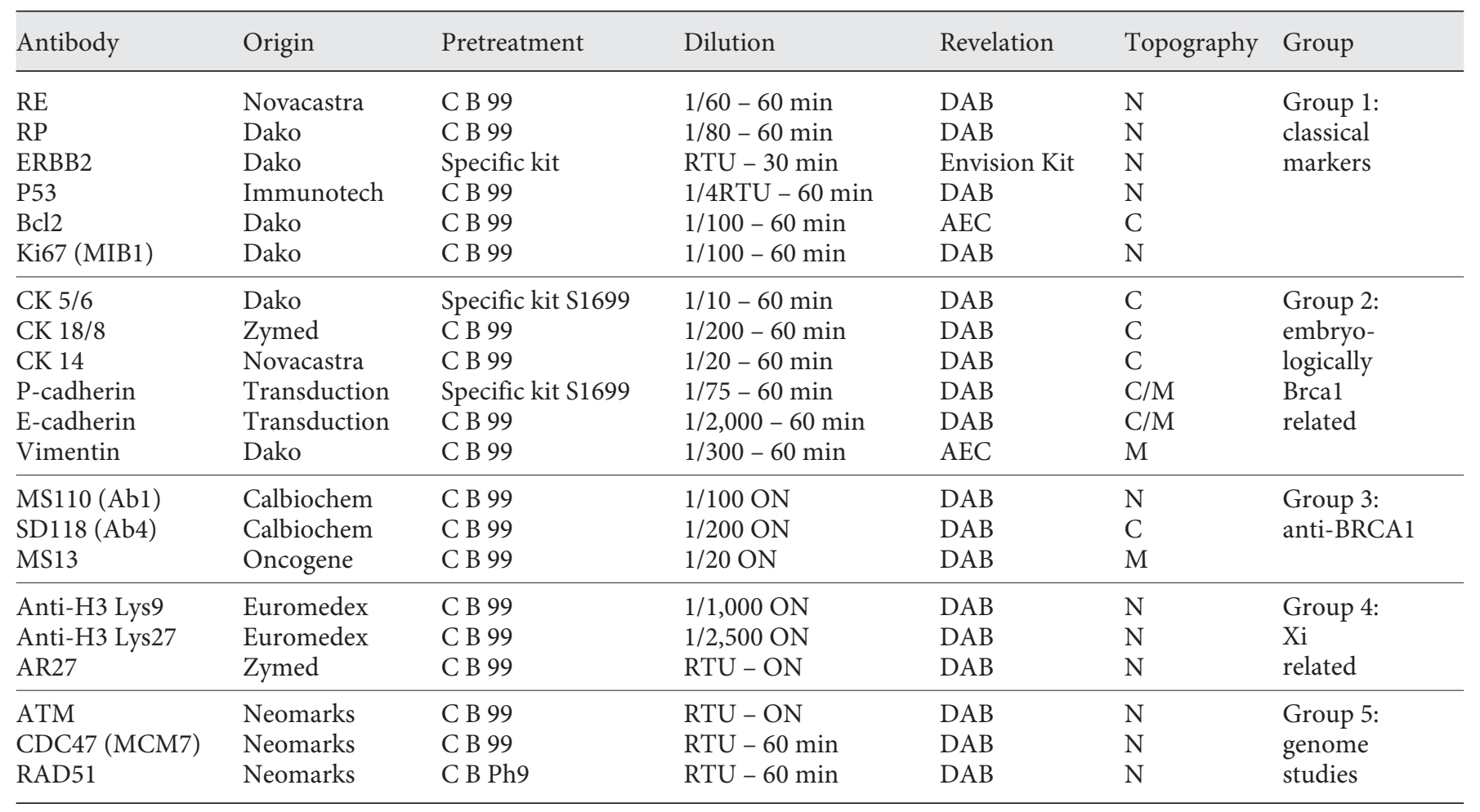

$\mathrm{C} \mathrm{B} 99=$ Citrate buffer $99^{\circ} \mathrm{C}, \mathrm{pH} 6,40 \mathrm{~min} ; \mathrm{RTU}=$ ready to use; $\mathrm{N}=$ nuclear; $\mathrm{C}=$ cytoplasmic $\mathrm{M}=$ mixed; $\mathrm{DAB}=$ diaminebenzidine tetrahydrocchlory; $\mathrm{AEC}=$ amino-9-ethyl carbazole; $\mathrm{ON}=$ overnight.

\section{Mutation Screening}

Genomic DNA was extracted from peripheral blood using a QIAamp DNA Mini Kit (QIAGEN).

Polymerase chain reaction (PCR) was performed in a $25-\mu 1$ reaction containing 25-ng templates of DNA, $0.8 \mu \mathrm{M}$ of each primer, $200 \mu \mathrm{M}$ dNTPs, standard PCR buffer, and $1 \mathrm{U}$ of thermostable DNA Taq polymerase. Amplification included an initial denaturation at $95^{\circ} \mathrm{C}$ for $10 \mathrm{~min}$ followed by 40 cycles of $30 \mathrm{~s}$ of denaturation at $95^{\circ} \mathrm{C}, 30 \mathrm{~s}$ of annealing at $55^{\circ} \mathrm{C}$, and $30 \mathrm{~s}$ of extension at $72^{\circ} \mathrm{C}$ in GeneAmp 9700 thermocycler (Applied Biosystems Inc., Foster City, Calif., USA).

Before DHPLC analysis, PCR products were subjected to an additional $10 \mathrm{~min}$ and $95^{\circ} \mathrm{C}$ of denaturation followed by gradual reannealing from 95 to $25^{\circ} \mathrm{C}$ over a period of $45 \mathrm{~min}$. DHPLC was carried out on an automated WAVE Maker System (Transgenomic Inc., San Jose, Calif., USA).

Abnormal chromatograms were analyzed by sequencing. Amplicons were purified with Sephadex G-50 Superfine (GE Healthcare, Uppsala, Sweden) and bidirectionally sequenced using a BigDye Terminator v1.1 Cycle Sequencing Kit on an automated ABI-3130 Genetic Analyzer (Applied Biosystems).

Tissue Microarray

The high throughput technique of TMA has been used to economize on the precious blocks of tissues where small samples can still be saved despite use of a large number of antibodies. We used the method as previously described by Jacquemier et al. [25] and Kononen et al. [26].

The markers used are presented in table 1.

In the initial set, 21 markers were selected and divided into five groups as follows:

(1) The first group was represented by six markers commonly examined in BC: ER, PR, Erbb2, P53, Bcl2, and Ki67 [10].

(2) The second group was represented by 6 markers related to basal, myoepithelial or mesechymal status (CK5/6, CK14, P-cadherin, and vimentin) and luminal phenotype (CK8/18, E-cadherine) $[25,27,28]$.

(3) The third group was represented by 3 anti-BRCA1 commercial protein antibodies [10], i.e. MS110, SD118, and MS13, all of which react to the N terminal of the protein [29] while SD118 is claimed to be specific to exon 11 deletions [30].

(4) The fourth group was represented by 3 antibodies related to inactivation of the $\mathrm{X}$ chromosome [31,32]. In women, 1 of $2 \mathrm{X}$ chromosomes is randomly inactivated; the inactive $\mathrm{X}$ has specific characters such as methylation of lysine 27 on histone 3 and the presence of a particular region called an inactivation center that contains a gene called XIST for X inactivation specific transcript coding for RNA that is not translated but covers and stabilizes the inactive X [6]. In tumors without wild BRCA1, XIST does not cover the X chromosome and the other markers of inactivation such as the methylated lysine $27 \mathrm{H} 3$ and lysine $9 \mathrm{H} 3$ are lost $[33,34]$ and used as indirect signs of an 


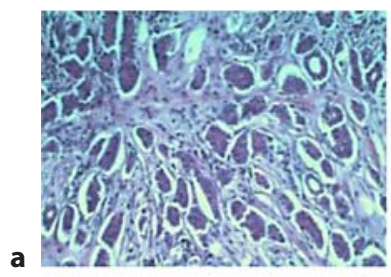

Grade 1

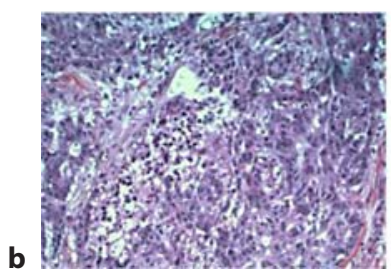

Grade 3

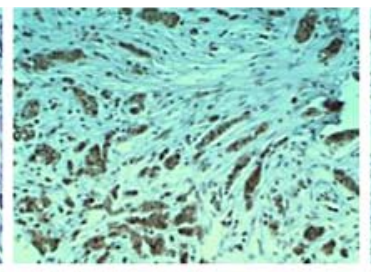

MS110 positive

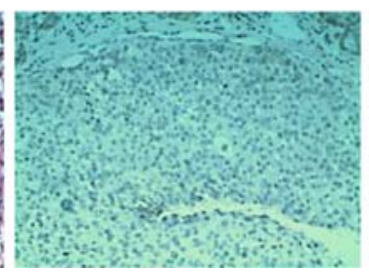

MS110 negative

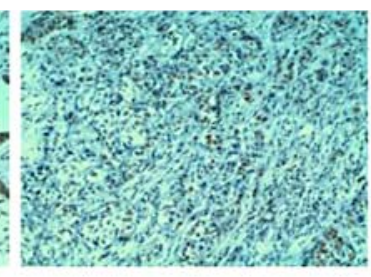

Lys27 positive

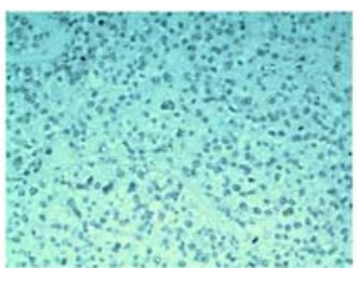

Lys27 negative

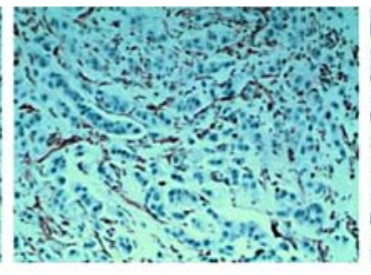

Vimentin negative

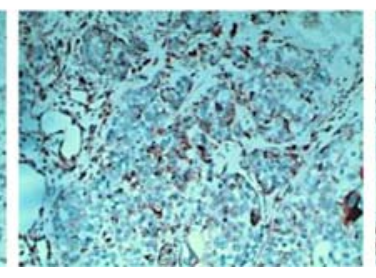

Vimentin positive

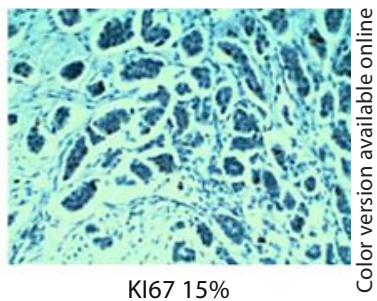

KI67 15\%

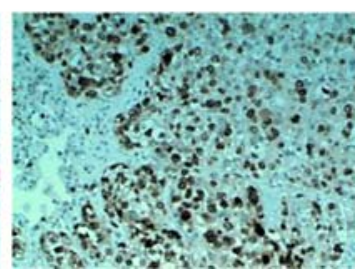

KI67 80\%

Fig. 1. Morphological aspects of sporadic (a) and BRCA1-mutated (b) cases.

inactive $\mathrm{X}$. The androgen receptor gene is located in Xcent $\mathrm{q} 13$ and its expression is an indication of the presence of one or two active $\mathrm{X}$ and mammary hormonal dependence [35].

(5) The last group was derived from transcriptional and genomic studies where some genes appeared to be of interest in BC [36]. We examined by IHC the markers ATM and RAD 51, which are associated with BRCA1 in double-strand repair while CDC47 is a protein essential for initiation of DNA replication. For the validation set, we used only the antibodies from the multivariable analysis, i.e. MS110, anti-Lys27, vimentin, and KI67, in the 28 muted and sporadic $\mathrm{BC}$ and for comparisons with other models we added ER, PR, and Erbb2.

\section{IHC Method}

IHC was performed on $5-\mu \mathrm{m}$ sections using the TMA method with 3 slides for each marker.

We de-waxed in histolemon and then used ethanol subjected to a high-temperature unmasking technique (see table 1 for pretreatment, dilution, and revelation). Endogenous peroxidases were eliminated by $\mathrm{H}_{2} \mathrm{O}_{2}$ and the side reactions were blocked by a mixture of different sera and then processed for incubation with the chosen markers for 30 or 60 min or overnight, depending on the trials we already performed to find out the best procedure. Amplification was followed by visualization using either DAB or AEC.

\section{Marker Evaluation}

It is performed using an automated system analyzer to best select the exact location of each core (Spot Browser, Alphelys, France). The results were evaluated using an optic microscope in a double reading session by two pathologists (M.H. and J.J.). These results were expressed as a percentage ' $\mathrm{P}$ ' of tumor cells with detectable staining ranging from $0 \%$ (undetectable) to $100 \%$ (complete staining). The intensity 'I' of staining was also scored as 1 for weak staining, 2 for moderate staining, and 3 for strong staining. For each marker, the mean of the reading score of at least 2 core biopsies was calculated.
The results were then processed using the quick score (QS) method, where $\mathrm{QS}=\mathrm{P} \times \mathrm{I}$ with a minimum of 0 and a maximum of 300, except for Erbb2 status which was evaluated using the Dako Scale (Herceptest kit scoring guidelines) and Ki67 which was read as positive or negative with a cutoff of $50 \%$.

Morphological aspects of some sporadic and BRCA1-mutated cases are represented in figure 1 .

\section{Statistical Analysis}

The data analysis was conducted in 4 stages. First, using the initial data set, univariate statistics were generated to describe the different parameters associated with BRCA1 status. Markers associated with BRCA1 status with $\mathrm{p}<0.05$ in the univariate analyses were then selected to create the best fit multivariate logistic regression model based on the maximum likelihood ratio criterion ('best fit model'). Second, we applied the model selected from the multivariate analysis of the initial set in the validation set to predict BRCA1 status.

We then compared the observed BRCA1 status obtained from blood sample genetic testing and the predicted status obtained from the statistical model to estimate the sensitivity and specificity of the model.

A similar process was performed to compare our 'best fit model' estimated from the initial data and applied to the validation set with the previously described models.

Thus, a second model including only grade and HR status and a third model including only HR and HER 2 status were estimated in the validation data set to predict BRCA1 status. Sensitivity and specificity were calculated for each model comparing the observed and expected BRCA1 status.

Statistical significance was set at 0.05 . All p-values are 2-sided. The statistical package used was SPSS release 16.0. 
Table 2. Characteristics of tumors included

\begin{tabular}{|c|c|c|c|c|c|c|c|c|c|c|c|c|}
\hline \multirow[t]{3}{*}{ Markers } & \multicolumn{6}{|c|}{$\begin{array}{l}\text { In the initial data set comprising } 27 \text { BRCA } 1 \text { and } 81 \text { sporadic } \\
\text { tumors }\end{array}$} & \multicolumn{6}{|c|}{$\begin{array}{l}\text { In the validation data set comprising } 28 \text { BRCA } 1 \text { and } 28 \text { sporadic } \\
\text { tumors }\end{array}$} \\
\hline & \multicolumn{2}{|c|}{ BRCA1 cases } & \multicolumn{2}{|c|}{ sporadic cases } & \multirow[t]{2}{*}{ OR } & \multirow[t]{2}{*}{$\mathrm{p}$} & \multicolumn{2}{|c|}{ BRCA1 cases } & \multicolumn{2}{|c|}{ sporadic cases } & \multirow[t]{2}{*}{ OR } & \multirow[t]{2}{*}{$\mathrm{p}$} \\
\hline & $\mathrm{n}$ & $\%$ & $\mathrm{n}$ & $\%$ & & & $\mathrm{n}$ & $\%$ & $\mathrm{n}$ & $\%$ & & \\
\hline Grade 3 & 22 & 81.5 & 28 & 34.6 & 8.3 & $<0.001$ & 21 & 75.0 & 12 & 42.9 & 4.0 & 0.015 \\
\hline ER negative & 17 & 73.9 & 13 & 19.4 & 11.8 & $<0.001$ & 24 & 85.7 & 4 & 14.3 & 36.0 & $<0.001$ \\
\hline PR negative & 18 & 75.0 & 24 & 33.8 & 5.9 & 0.001 & 23 & 85.2 & 7 & 25.0 & 17.3 & $<0.001$ \\
\hline HR negative & 15 & 68.2 & 11 & 15.5 & 11.7 & $<0.001$ & 22 & 81.5 & 4 & 14.3 & 26.4 & $<0.001$ \\
\hline ERBB2 negative $0 / 1$ & 20 & 95.2 & 56 & 83.6 & 3.9 & 0.204 & 27 & 96.4 & 25 & 89.3 & 3.2 & 0.30 \\
\hline P53 positive & 15 & 62.5 & 14 & 20.3 & 6.5 & $<0.001$ & & & & & & \\
\hline $\mathrm{Bcl} 2$ negative & 16 & 64.0 & 12 & 16.2 & 9.2 & $<0.001$ & & & & & & \\
\hline Ki67 MIB1 $\geq 60$ & 4 & 18.2 & 2 & 3.1 & 6.9 & 0.03 & 17 & 60.7 & 5 & 17.9 & 7.1 & 0.001 \\
\hline CK 5/6 negative & 15 & 60.0 & 36 & 49.3 & 1.5 & 0.36 & & & & & & \\
\hline CK 14 positive & 5 & 20.0 & 11 & 14.7 & 1.5 & 0.53 & & & & & & \\
\hline P-cadherin $>100$ & 16 & 61.5 & 12 & 18.2 & 7.2 & $<0.001$ & & & & & & \\
\hline E-cadherin $\geq 100$ & 6 & 24.0 & 7 & 10.0 & 2.8 & 0.09 & & & & & & \\
\hline Vimentin positive & 16 & 69.6 & 14 & 19.7 & 9.3 & $<0.001$ & 14 & 53.9 & 5 & 17.9 & 5.4 & 0.006 \\
\hline MS110 Ab1 negative & 17 & 68.0 & 9 & 12.0 & 15.6 & $<0.001$ & 19 & 67.9 & 3 & 10.7 & 17.6 & $<0.001$ \\
\hline SD118 Ab4 negative & 4 & 15.4 & 3 & 4.3 & 4.1 & 0.08 & & & & & & \\
\hline MS13 negative & 7 & 29.2 & 7 & 10.8 & 3.4 & 0.04 & & & & & & \\
\hline Anti-H3 Lys9 negative & 17 & 65.4 & 16 & 21.1 & 7.1 & $<0.001$ & & & & & & \\
\hline Anti-H3 Lys27 negative & 11 & 42.3 & 6 & 7.7 & 8.8 & $<0.001$ & 13 & 48.2 & 3 & 10.7 & 7.7 & 0.002 \\
\hline CDC47 negative & 12 & 50.0 & 14 & 21.2 & 3.7 & 0.01 & & & & & & \\
\hline
\end{tabular}

\section{Results}

\section{Learning Initial Set Analysis}

The results of the univariate analysis are presented in table 2.

Grade 3 and 12 markers were associated with BRCA1 status in the univariate analysis $(\mathrm{p}<0.05)$.

Grade 3 tumors were significantly more common among BRCA1-mutated tumors.

The histological type is dominated by invasive ductal carcinoma in both groups; 5 medullary cases were diagnosed among the BRCA1-mutated tumors (18.5\%) and none were diagnosed in the sporadic group.

Among the first group of commonly used markers, 5 out of 6 were also significantly associated with BRCA1 mutated tumors: ER, PR, P53, Bcl2, and Ki67.

In the second group, BRCA1-mutated tumors had a higher level of P-cadherin and were more often vimentin positive. Other basal and luminal markers (CK5/6, CK14, and E-cadherin) were not associated with BRCA1 status.

Among the commercial anti-BRCA1 antibodies (MS110, SD118, and MS13) MS110 was the most strongly associated with BRCA1 status.

In our study the localization of MS110 in normal breast tissues was nuclear, whereas it was either nuclear or mixed (nuclear and cytoplasmic) in the case of mutations when the expression was present. MS13 also yielded significant results: it was negative in $29.2 \%$ of BRCA1-mutated cases versus only $10.8 \%$ negative in sporadic ones.

We did not find a correlation between the mutations, which occur in exon 11, and the staining results of the SD118 marker despite the claims of the manufacturing laboratory.

Among the three X-inactivation-related markers (anti-Lys9H3, anti-Lys27H3, and AR27), only anti-H3 Lys9 and anti-H3 Lys27 showed an association with BRCA1 status.

In the fifth group of genomic markers, CDC47 only was more frequently negative among BRCA1 mutated tumors.

\section{Multivariate Analysis}

After adjustment of the variable for pairing 'age' chosen before the start of the study, the variables significantly linked to BRCA1 mutation status were: grade 3, MS110: more negative in the mutated group; anti-H3 Lys27: more negative in mutated cases; vimentin: more positive in the mutated tumors, and KI67: more positive in the mutated group.

This equation was then applied to the validation set. 
Table 3. Comparison of different models

\begin{tabular}{|c|c|c|c|c|c|c|c|}
\hline & \multirow[t]{2}{*}{ Status } & \multicolumn{2}{|c|}{$\begin{array}{l}\text { Model } 1^{\mathrm{a}} \\
\text { (best fit model) }\end{array}$} & \multicolumn{2}{|c|}{$\begin{array}{l}\text { Model } 2^{\mathrm{a}} \\
\text { (grade - HR) }\end{array}$} & \multicolumn{2}{|c|}{$\begin{array}{l}\text { Model } 3^{\mathrm{a}} \\
\text { (triple negative) }\end{array}$} \\
\hline & & OR & $\mathrm{p}$ & OR & $\mathrm{p}$ & OR & $\mathrm{p}$ \\
\hline \multicolumn{8}{|l|}{ In the initial data set } \\
\hline Grade & 3 & 6.8 & 0.015 & 6.0 & 0.015 & - & - \\
\hline HR & Negative & 2.0 & 0.53 & 8.3 & 0.002 & 18.9 & $<0.001$ \\
\hline MS110 (Ab1) & Negative & 16.6 & 0.01 & - & - & - & - \\
\hline Anti-H3 Lys27 & Negative & 8.7 & 0.049 & - & - & - & - \\
\hline Vimentin & Positive & 11.0 & 0.016 & - & - & - & - \\
\hline Ki67 & Positive $\geq 50$ & 39.2 & 0.01 & - & - & - & - \\
\hline Erbb2 & Negative & - & - & - & - & 1.3 & 0.83 \\
\hline \multicolumn{8}{|l|}{ In the validation set } \\
\hline Sensitivity & & 0.83 & & 0.63 & & 0.56 & \\
\hline Specificity & & 0.81 & & 0.88 & & 0.75 & \\
\hline
\end{tabular}

\section{Validation Set}

The results of the 28 BRCA1-associated BC and the sporadic $\mathrm{BC}$ confirmed the signature obtained in the initial set (table 2).

\section{Comparison of Our Model with Other Profiles}

When applying once again the multivariate logistic regression model to obtain the best fit model among the previously described models and our results, more than $80 \%$ of BRCA1 mutated tumors were correctly classified (i.e. BRCA1-mutated BC vs. sporadic BC) with our group of markers. By comparison with grade 3 alone in our series, with a sensitivity of $44 \%$ and a specificity of $91 \%$, the second model, comprising grade and HR status [19], and the third, the triple negative model [21], provided a sensitivity of only 63 and $56 \%$ respectively. All of these models are summarized in table 3.

\section{Discussion}

Our goal was to find a rapid, reliable prescreening method to better select patients with BRCA1 mutationassociated BC.

This kind of approach is needed to overcome the long delay observed in obtaining genetic analysis results and the difficulties encountered by doctors in providing appropriate treatment to patients and advice to their families. Detection of the BRCA1 protein by IHC methods is a subject of controversy because its revelation depends not only on the concentration and specificity of the antibody used but also on the technical parameters applied in IHC $[10,37,38]$ and the level of development and age of the mammary cells examined [7]. Some of the specificity of the anti-BRCA1 antibodies is supposed to be related to the type of mutation (involving exon 11 or not) [30] or the fragmentation of this big protein [39]. In addition, the localization of this protein was variously appreciated: it was nuclear in normal and cancerous cells $[12,39]$ or nuclear in normal cells and cytoplasmic in cancerous cells [40] or, in some cases, in cytoplasmic invaginations of nuclear membrane [41].

These various considerations and reflections explain the difficulties encountered up to now in finding a simple IHC method to allow the rapid detection of tumors associated with a BRCA1 germ-line mutation.

The equation we suggested to decide on a genetic test is better than prediction based on family history $(<10 \%)$ [42], the BRCAPRO test (33\%) [43], and triple negatives, the score of which is less than $10 \%$ in different studies [44].

Basal BC phenotypes in BRCA1 germ-line mutation tumors were found only in $44 \%$ [22] to $55 \%$ [23] of patients depending on the definition of BP used by different authors. Combining some of these tumoral phenotype characteristics (ER negative, grade 3 ) with an onset of BC before the age of 35, the BRCA1 germ-line mutation carrier status was correctly identified in $28.6 \%$ cases [19].

All 5 groups of markers originally combined in a selection with a probable discriminating character in the ini- 
tial set yielded encouraging results either in agreement with the literature or by identifying new ones.

In the group of classical BC markers, it has been established by many authors and confirmed by the present study that BRCA1-mutated tumors are associated with ER, PR, and Erbb2 negativity, corresponding to the triple negative definition and approaching the IHC profile of basal type breast carcinomas. However, not all triple-negative tumors are associated with a BRCA1 germ-line mutation, and not all BRCA1-associated BC are triple-negative tumors or basal ones. To achieve the best combination of high sensitivity and specificity, the present model is more efficient than that based on the triple negative profile [21] or that previously proposed based on both grade and hormonal receptor status [42].

The results of $\mathrm{P}$-cadherin and vimentin, which are two markers of the basal/myoepithelial and epithelio-mesenchymal transition between basal and luminal cells, strengthen the previous reports published by Jacquemier et al. [24, 25] and those of Lakhani et al. [23] and Foulkes et al. [45] as well as that of Korsching et al. [27] on vimentin.

From many years the origin of $\mathrm{BC}$ cells has been discussed, i.e. whether they come from luminal cells that show differentiation towards various strains or from a stem cell progenitor or the origin is a basal/myoepithelial cell, depending on the type of $\mathrm{BC}$.

Transformation of the BRCA1 mutation-associated cells occurs early during development probably before the stage of differentiation into basal or myoepithelial cells or even earlier with a mesenchymal relationship.

With vimentin, which is a mesenchymal marker, the origin and time of the transformation of the cancer cells was supposed to be earlier in the differentiation field and hence nearer to the stem progenitor cells. This can suggest a regulator stem cell function of the BRCA1 gene [46].

For loss of inactivation of the $\mathrm{X}$ chromosome, we showed via IHC for the first time in tumor tissues the likelihood of a correlation between the BRCA1 gene and inactivation of the $\mathrm{X}$ chromosome, and this strengthens the results - which are still being debated - of the studies of Heard et al. [33] and Plath et al. [34] on X inactivation as well as those of Stone et al. [32] on cell lines. However additional studies are needed to improve the understanding of these mechanisms in hopes of discovering possible new therapies.

In the fifth group of markers, we confirmed the potential usefulness of CDC47 in validating the previous results obtained through transcriptional and proteomic studies.

Prediction of BRCA1 Germ-Line Mutation Status
Our IHC equation (grade 3 and MS 110, LYS 27H3, vimentin, and KI67) predicts a risk of BRCA1 mutation of more than $80 \%$. The interrelationship between BRCA1-related, BP, and triple-negative tumors [47] is highly emphasized here because we examined the prevalence of $\mathrm{BP}$ and triple-negative BC in BRCA1-associated tumors and not only the incidence of BRCA1-related BC in BP and triple-negative $\mathrm{BC}$.

In spite of their usefulness, probability estimation models have certain weakness such as that they are all developed on the basis of family histories reported by patients, and such histories are often inaccurate because of missing data, and many family histories are interpreted in different ways by different genetic counselors.

The computer-based BRCAPRO model showed substantial under-estimation of risk in the lower risk groups and over-estimation in the highest risk group. This explains why BRCA1 mutation probability prediction models can yield misleading and discordant results in some families, especially at the extremes of the probability scale [15].

\section{Conclusion and Perspectives}

Our study has the advantage of offering a 'multimarker' approach and hence the results do not depend only on the anti-BRCA1 protein antibodies but also on a group of markers with different targets that are associated in embryogenesis or even oncogenesis.

After the study of Young et al. [44] on the prevalence of BRCA1 gene mutation, a minority of $\mathrm{BC}$ patients reported a positive reliable family history and in only $10 \%$ of cases where molecular biology analysis was done after the family history were the results positive for the mutation. In accordance with that, we have to suggest another method more reliable than the family history as a clue for a positive predictive test of mutation.

Immunostaining provides better sensitivity, specificity, and positive predictive values than the family history in late onset as well as early onset patients.

A few antibodies would allow a very interesting clinical access to shortlist patients who would benefit straight away from a specific treatment in a more appropriate and more effective manner and to help their families with early management.

The phenotype we suggest will help the doctors in their decision of whether to use anti-PARP (poly ADPribose polymerase), anthracyclins, cisplatin [18], or taxanes in first line treatment as we know that the mutated 
and mutated-like phenotype tumors respond less to taxanes than the different chemotherapies already mentioned [48].

PARP proteins - via the base excision-repair system - are a cornerstone of DNA's single-strand break repair. Inhibition of PARP leads to the accumulation of single-strand breaks, with secondary double-strand breaks at the DNA-replication forks. Repair of double-strand breaks is performed by homologous recombination that is controlled by BRCA1 and BRCA2 [49] Tumors with BRCA1/BRCA2 mutations are very sensitive to PARP inhibitors. When BRCA1 or BRCA2 is lost, PARP-I exposition leads to lethal DNA lesions and cellular death. This concept has been validated in clinical trials, with olaparib in women with BRCA1- or BRCA2-mutated BC [48].
Addition of the four antibodies (MS110, lys27H3, vimentin, and KI67) to other routinely tested antibodies (RE, RP, Erbb2, and grade) to decide on genetic analysis for those tumors that comply with our equation will cost little but may help greatly.

\section{Acknowledgements}

We thank all of the patients who allowed us to use their tissues in this analysis. We also thank the members of the genes and cancer group in France who participated in the elaboration of this study. We are especially grateful to the biopathology and oncogenetics departments of the Paoli Calmettes Institute and to Marie Paule Terrazzoni and Jocelyne Gauthier for their help. Many thanks also to Margareta Bettacchini for the review of the English translation.

\section{References}

1 Hery C, Ferlay J, Boniol M, Autier P: Quantification of changes in breast cancer incidence and mortality since 1990 in 35 countries with Caucasian-majority populations. Ann Oncol 2008;19:1187-1194.

-2 Miki Y, Swensen J, Shattuck-Eidens D, et al: A strong candidate for the breast and ovarian cancer susceptibility gene BRCA1. Science 1994;266:66-71.

- 3 Easton DF, Ford D, Bishop DT: Breast and ovarian cancer incidence in BRCA1-mutation carriers - Breast Cancer Linkage Consortium. Am J Hum Genet 1995;56:265-271.

4 Milne RL, Osorio A, Cajal TR, et al: The average cumulative risks of breast and ovarian cancer for carriers of mutations in BRCA1 and BRCA2 attending genetic counseling units in Spain. Clin Cancer Res 2008; 14: 2861-2869.

-5 Bertwistle D, Ashworth A: Functions of the BRCA1 and BRCA2 genes. Curr Opin Genet Dev 1998;8:14-20.

-6 Ganesan S, Silver DP, Drapkin R, Greenberg R, Feunteun J, Livingston DM: Association of BRCA1 with the inactive X chromosome and XIST RNA. Philos Trans R Soc Lond B Biol Sci 2004;359:123-128.

-7 Mueller CR, Roskelley CD: Regulation of BRCA1 expression and its relationship to sporadic breast cancer. Breast Cancer Res 2003;5:45-52.

8 Couch FJ, Hartmann LC: BRCA1 testing advances and retreats. JAMA 1998;279:955957.

-9 Yoshikawa K, Honda K, Inamoto T, et al: Reduction of BRCA1 protein expression in Japanese sporadic breast carcinomas and its frequent loss in BRCA1-associated cases. Clin Cancer Res 1999;5:1249-1261.
10 Abd El-Rehim DM, Ball G, Pinder SE, et al: High-throughput protein expression analysis using tissue microarray technology of a large well-characterised series identifies biologically distinct classes of breast cancer confirming recent cDNA expression analyses. Int J Cancer 2005;116:340-350.

11 Dobrovic A, Simpfendorfer D: Methylation of the BRCA1 gene in sporadic breast cancer. Cancer Res 1997;57:3347-3350.

12 Scully R, Ganesan S, Brown M, et al: Location of BRCA1 in human breast and ovarian cancer cells. Science 1996;272:123-126.

13 Knudson A: Alfred Knudson and his two-hit hypothesis (interview by Ezzie Hutchinson). Lancet Oncol 2001;2:642-645.

14 Antoniou AC, Hardy R, Walker L, et al: Predicting the likelihood of carrying a BRCA1 or BRCA2 mutation: validation of BOADICEA, BRCAPRO, IBIS, Myriad and the Manchester scoring system using data from UK genetics clinics. J Med Genet 2008;45:425431.

15 Lindor NM, Lindor RA, Apicella C, et al: Predicting BRCA1 and BRCA2 gene mutation carriers: comparison of LAMBDA, BRCAPRO, Myriad II, and modified Couch models. Fam Cancer 2007;6:473-482.

16 Pasini B, Casalis Cavalchini GC, Genovese T, Manoukian S: Evaluating breast cancer risk: available models to assess individual breast cancer risk and probability to be a BRCA mutation carrier. J Exp Clin Cancer Res 2002;21:23-29.

17 Mitchell G, Ardern-Jones A, Kissin MM, Taylor R, Eeles RA: A paradox: urgent BRCA genetic testing. Fam Cancer 2001;1:25-29.

18 Sgagias MK, Wagner KU, Hamik B, et al: Brcal-deficient murine mammary epithelial cells have increased sensitivity to CDDP and MMS. Cell Cycle 2004;3:1451-1456.
9 Lidereau R, Eisinger F, Champeme MH, et al: Major improvement in the efficacy of BRCA1 mutation screening using morphoclinical features of breast cancer. Cancer Res 2000; 60:1206-1210.

20 Wilson CA, Ramos L, Villasenor MR, et al: Localization of human BRCA1 and its loss in high-grade, non-inherited breast carcinomas. Nat Genet 1999;21:236-240.

21 Reis-Filho JS, Tutt AN: Triple negative tumours: a critical review. Histopathology 2008;52:108-118.

22 Tischkowitz MD, Foulkes WD: The basal phenotype of BRCA1-related breast cancer: past, present and future. Cell Cycle 2006;5: 963-967.

23 Lakhani SR, Gusterson BA, Jacquemier J, et al: The pathology of familial breast cancer: histological features of cancers in families not attributable to mutations in BRCA1 or BRCA2. Clin Cancer Res 2000;6:782-789.

24 Jacquemier J, Padovani L, Rabayrol L, et al: Typical medullary breast carcinomas have a basal/myoepithelial phenotype. J Pathol 2005;207:260-268

25 Jacquemier J, Eisinger F, Nogues C, et al: Histological type and syncytial growth pattern affect E-cadherin expression in a multifactorial analysis of a combined panel of sporadic and BRCA1-associated breast cancers. Int J Cancer 1999;83:45-49.

26 Kononen J, Bubendorf L, Kallioniemi A, et al: Tissue microarrays for high-throughput molecular profiling of tumor specimens. Nat Med 1998;4:844-847. 
27 Korsching E, Packeisen J, Liedtke C, et al: The origin of vimentin expression in invasive breast cancer: epithelial-mesenchymal transition, myoepithelial histogenesis or histogenesis from progenitor cells with bilinear differentiation potential? J Pathol 2005;206: 451-457.

28 Palacios J, Honrado E, Osorio A, et al: Phenotypic characterization of BRCA1 and BRCA2 tumors based in a tissue microarray study with 37 immunohistochemical markers. Breast Cancer Res Treat 2005;90:5-14.

29 Bernard-Gallon DJ, Peffault de LM, De OF, et al: BRCA1 is localized in ductal secretions of normal breast tissues: detection by antibodies raised against the amino terminus of BRCA1 (K-18). Int J Cancer 1998;77:803806.

30 Kashima K, Oite T, Aoki Y, et al: Screening of BRCA1 mutation using immunohistochemical staining with C-terminal and Nterminal antibodies in familial ovarian cancers. Jpn J Cancer Res 2000;91:399-409.

- 31 Jazaeri AA, Chandramouli GV, Aprelikova $\mathrm{O}$, et al: BRCA1-mediated repression of select X chromosome genes. J Transl Med 2004;2:32.

32 Stone C, McCabe N, Ashworth A: X-chromosome inactivation: $\mathrm{X}$ marks the spot for BRCA1. Curr Biol 2003;13:R63-R64.

- 33 Heard E, Rougeulle C, Arnaud D, Avner P, Allis CD, Spector DL: Methylation of histone $\mathrm{H} 3$ at Lys-9 is an early mark on the $\mathrm{X}$ chromosome during $\mathrm{X}$ inactivation. Cell 2001; 107:727-738.
34 Plath K, Fang J, Mlynarczyk-Evans SK, et al: Role of histone $\mathrm{H} 3$ lysine 27 methylation in $\mathrm{X}$ inactivation. Science 2003;300:131-135.

- 35 Berns EM, Arkzwager-Kiel MJ, KuenenBoumeester V, et al: Androgen pathway dysregulation in BRCA1-mutated breast tumors. Breast Cancer Res Treat 2003;79:121127.

36 Hedenfalk I, Duggan D, Chen Y, et al: Geneexpression profiles in hereditary breast cancer. N Engl J Med 2001;344:539-548.

37 Perez-Valles A, Martorell-Cebollada M, Nogueira-Vazquez E, Garcia-Garcia JA, Fuster-Diana E: The usefulness of antibodies to the BRCA1 protein in detecting the mutated BRCA1 gene: an immunohistochemical study. J Clin Pathol 2001;54:476-480.

38 Yoshikawa K, Ogawa T, Baer R, et al: Abnormal expression of BRCA1 and BRCA1-interactive DNA-repair proteins in breast carcinomas. Int J Cancer 2000;88:28-36.

-39 Thakur S, Zhang HB, Peng Y, et al: Localization of BRCA1 and a splice variant identifies the nuclear localization signal. Mol Cell Biol 1997;17:444-452.

40 Chen Y, Chen CF, Riley DJ, et al: Aberrant subcellular localization of BRCA1 in breast cancer. Science 1995;270:789-791.

41 Coene E, Van OP, Willems K, van EJ, De Potter CR: BRCA1 is localized in cytoplasmic tube-like invaginations in the nucleus. Nat Genet 1997;16:122-124.
42 Peto J, Collins N, Barfoot R, et al: Prevalence of BRCA1 and BRCA2 gene mutations in patients with early-onset breast cancer. J Natl Cancer Inst 1999;91:943-949.

43 Berry DA, Iversen ES Jr, Gudbjartsson DF, et al: BRCAPRO validation, sensitivity of genetic testing of BRCA1/BRCA2, and prevalence of other breast cancer susceptibility genes. J Clin Oncol 2002;20:2701-2712.

44 Young SR, Pilarski RT, Donenberg T, et al: The prevalence of BRCA1 mutations among young women with triple-negative breast cancer. BMC Cancer 2009;9:86.

45 Foulkes WD, Stefansson IM, Chappuis PO, et al: Germline BRCA1 mutations and a basal epithelial phenotype in breast cancer. J Natl Cancer Inst 2003;95:1482-1485.

46 Foulkes WD: BRCA1 functions as a breast stem cell regulator. J Med Genet 2004;41:1-5.

47 Diaz LK, Cryns VL, Symmans WF, Sneige N: Triple negative breast carcinoma and the basal phenotype: from expression profiling to clinical practice. Adv Anat Pathol 2007;14: 419-430.

48 Lord CJ, Ashworth A: Targeted therapy for cancer using PARP inhibitors. Curr Opin Pharmacol 2008;8:363-369.

49 Berrada N, Delaloge S, Andre F: Treatment of triple-negative metastatic breast cancer: toward individualized targeted treatments or chemosensitization? Ann Oncol 2010, 21(suppl 7):vii30-vii35. 